\title{
Apropiación y ampliación del territorio por ejidatarios de Bachoco, Guasave, Sinaloa
}

\section{The Appropriation and Expansion of Territory by the Ejidatarios of Bachoco, Guasave, Sinaloa}

Jesús López Estrada

Universidad Autónoma de Sinaloa

jeloes6r@yahoo.com

DOI: I0.2490I/rehs.v40iI59.439

\section{(cc) EY-NC}

Apropiación y ampliación del territorio por ejidatarios de Bachoco, Guasave, Sinaloa por Jesús López Estrada se distribuye bajo una Licencia Creative Commons Atribución-NoComercial 4.0 Internacional.

Fecha de recepción: 28 de mayo de 2018

Fecha de aprobación: 4 de febrero de 2019

\section{RESUMEN:}

Este artículo aborda la dotación del ejido Bachoco; el reacomodo de campesinos que llegaron al irrigarse las tierras; la ampliación del territorio por medio del agrarismo y de la adquisición de predios rústicos; y las reformas neoliberales instrumentadas por el Estado. En este proceso, el paisaje rural sufre cambios inducidos desde el Estado, los ejidatarios se adaptarán a los cambios, además de apropiarse y ampliar el territorio.

Palabras clave:

Campesinos, ejidatarios, ejido, paisaje rural, territorio. 


\section{ABSTRACT:}

This article addresses various interrelated topics: the endowment of the Bachoco ejido, the resettlement of peasants who came to irrigate those lands, the expansion of territory through agrarianism and acquisitions of rustic properties, and the neoliberal reforms implemented by the State. In this process, the rural landscape underwent changes induced by the State to which the ejidatarios had to adapt while also appropriating and expanding their territory.

Keywords:

Peasants, ejidatarios, ejido, rural landscape, territory.

Introducción ${ }^{1}$

La construcción de la presa Miguel Hidalgo y Costilla, en el municipio de El Fuerte, fue la obra hidráulica que logró la incorporación al cultivo de miles de hectáreas que permanecían vírgenes en el norte de Sinaloa. La posterior construcción de canales, drenes y calles perfilaron el Valle del Fuerte, asentado en una superficie de 228,337 ha, bajo el sistema de riego por gravedad, de las cuales 152,992 pertenecen a un total de i7,84I ejidatarios del sector social y 75,345 ha son de 3,759 propietarios del sector privado. El sector social está constituido por ejidatarios y campesinos sin tierra; el sector privado por grupos de propietarios privados unificados en su oposición al social. ${ }^{2}$ La confrontación de dichos sectores es resultado de sus disputas por la posesión de la tierra.

En relación con la propiedad de la tierra; en la correlación entre miembros del sector privado y los del sector social en el Valle del Fuerte predominan estos últimos, como resultado de su disputa por las tierras de buena calidad, que inició durante el cardenismo. El presidente Lázaro Cárdenas del Río dotó de tierras en 1937 a varios ejidos de la zona de Los Mochis, con un total de 83,442 ha para 4,663 ejidatarios, ${ }^{3}$ algunos de esos ejidos como Jiquilpan, Mochis y Morelos, prácticamente, han sido absorbidos por la mancha urbana de la ciudad de los Mochis, en otros ejidos como el 20 de Noviembre, Águila Azteca y Primero de Mayo gran parte de sus ejidatarios han vendido sus parcelas a particulares. Por lo que un estudio como el que aquí se presenta, donde los ejidatarios han logrado apropiarse y ampliar el territorio, resulta relevante para comprender las diferentes realidades que se están construyendo en el campo mexicano.

Este trabajo es producto parcial de una investigación más amplia, cuyo objetivo fue estudiar la dinámica del mercado de tierras del ejido Bachoco, Guasave, buscando comprender los mercados formales e informales de tierras y sus modalidades: compraventa y arrendamiento. En dicha investigación, como hijo de ejidatario conocí información relevante, que recopilé mediante entrevistas a informantes clave sobre las luchas agrarias de los campesinos, quienes conforme al marco legal se organizaban en Nuevos Centros de Población Ejidal (NCPE); cotizaban cuotas para que los dirigentes realizarán los trámites ante las instancias de gobierno (con el apoyo de alguna central campesina); y, de ser necesario, invadían los predios de 
propiedad privada. También supe de la participación de algunos ejidatarios en la compra de tierras de propiedad privada, ambos procesos lograron ampliar el territorio simbólico de Bachoco, lo mismo antes que después de reformado el Artículo 27 constitucional.

En México, se reformó el Artículo 27 constitucional y se expidió una ley agraria que significó el fin del reparto agrario. ${ }^{4} \mathrm{Al}$ inicio de ese proceso, se socializó en los ejidos la propuesta de modificación por personal de la Secretaría de la Reforma Agraria (SRA), lo que me permitió participar en una asamblea general de ejidatarios en Bachoco. En la asamblea, con la información del semanario Proceso comenté la posible privatización de los ejidos y el fin del reparto agrario. La asamblea resolvió por unanimidad, que en coordinación con las autoridades ejidales manifestáramos nuestra inconformidad contra dichas reformas. Las autoridades ejidales rentaron un autobús para facilitar el traslado de ejidatarios a la Cámara de Diputados, que sesionaba en el auditorio del Centro Médico Nacional Siglo XXI en la Ciudad de México, donde se reformó el Artículo 27 constitucional, que finalizó el reparto agrario.

Abordé este estudio desde el construccionismo como enfoque teórico, apoyado en el actor social como categoría. Esta categoría me permitió explicar la constitución de grupos de campesinos de diferente origen, nivel económico, político, social y cultural, que unidos desplegaron diversas actividades, construyendo una identidad colectiva que cohesionó sus aspiraciones de mejorar el nivel de vida; primero para tener su parcela y, enseguida, hacerla producir.

El presente trabajo trata, primero, la dotación ejidal; enseguida, el proceso de reacomodo de los hijos de los ejidatarios y de otros grupos de campesinos que llegaron junto con las obras de irrigación. Posteriormente, la ampliación del territorio por medio de dos procesos diferenciados: a) las luchas agrarias, proceso en el que muchos campesinos, que se hicieron ejidatarios, participaron activamente en las tomas e invasiones de tierras de propiedad privada, ampliando el territorio agrario; y b) las diferentes adquisiciones de predios de propiedad privada, ya que algunos ejidatarios han logrado comprar varios lotes de tierra, que amplió simbólicamente el territorio de Bachoco. Finaliza el trabajo con la descripción de los diferentes tipos de ejidatarios que interactúan en el ejido, quienes de acuerdo con su clasificación, igual pueden establecer alianzas que confrontaciones entre sí o con los de otro tipo al tratar de adquirir tierras de buena calidad.

A lo largo del trabajo se describen los cambios en el paisaje rural decididos por el gobierno federal y experimentados por los campesinos, ya que este elemento, desde la dotación ejidal hasta las reformas neoliberales, ha tenido un papel relevante, lo mismo en el proceso de apropiación de las parcelas al interior del ejido que para ampliar el territorio.

\section{La dotación ejidal}

La dotación de tierras a un ejido representa el fin de una etapa de lucha de los demandantes de tierras, y la decisión gubernamental de satisfacer la demanda. ${ }^{5}$ El ejido es un tipo de tenencia de la tierra, que fue concebido como instrumento de estabilidad política y justicia social para 
acceder a la tierra. ${ }^{6}$ Es una forma de propiedad social de la tierra, otorgada a colectividades, que hasta 1992, impedían que dichas tierras se transfirieran, vendieran, rentaran o embargaran. ${ }^{7} \mathrm{El}$ ejidatario era el único que gozaba del derecho a usufructuar la tierra, participar en la asamblea y decidir sobre los asuntos del ejido. $\stackrel{-}{ }$ Las reformas legalizaron las formas de posesión, así como su mercado que estaba al margen de la ley y la posesión ilegal de tierras. ${ }^{2}$ Como forma de tenencia ha permitido la coexistencia de diversas formas de apropiación y uso de la tierra. ${ }^{\text {I0 }}$

La relación con la tierra define a los campesinos como una entidad histórica particular, una forma de producción en el marco amplio de una formación socioeconómica, con estructura y momentos propios, donde emerge, predomina, se desintegra y vuelve a emerger. ${ }^{\amalg I}$ El campesinado puede entenderse así, como un proceso social con una capacidad particular para permanecer y a la vez cambiar a lo largo de la historia. ${ }^{-2}$ Los campesinos viven y son parte del sistema, se han adecuado al crecimiento de los mercados y de las poblaciones urbanas. ${ }^{13} \mathrm{La}$ posesión de la tierra es concebida como un bien que sirve de condición necesaria y suficiente para ser campesino, además de comportar un prestigio especial, esto representa mucho más que una simple mercancía. ${ }^{ \pm 4}$ Por lo que los campesinos lucharán por tener su parcela, que les otorga prestigio independientemente de la cantidad y calidad de la tierra, así como del tipo de tenencia, que puede ser: propiedad privada, ejidal o comunal.

Un grupo de campesinos del poblado Bachoco solicitó dotación de tierras al gobernador de Sinaloa, turnó la solicitud a la Comisión Local Agraria, que instauró el expediente el 29 de febrero de 1932. La solicitud se publicó el i de marzo de ese año ${ }^{15} \mathrm{y}$ los demandantes esperaron poco más de diez años, desde que solicitaron la tierra hasta que les fue dotado el ejido. El ig de agosto de 1942 , el ejido Bachoco fue dotado con 4,690 hectáreas de tierra, $\frac{16}{}$ donde predominaba la selva baja caducifolia, colindando con esteros y marismas, la precipitación pluvial era muy baja por lo que dichos terrenos no eran aptos para la agricultura de temporal. La mayor parte de los nuevos ejidatarios eran indígenas mayos, aunque quienes ocuparon los cargos como autoridades ejidales, eran mestizos que residían en la ciudad de Los Mochis, o que tenían poco tiempo viviendo en Bachoco.

Las principales actividades económicas en la comunidad de Bachoco eran la ganadería extensiva, algunos campesinos se dedicaban a cortar leña que vendían directamente en Los Mochis llevándola en sus carretas, o bien la vendían en la comunidad a intermediarios; quienes tenían ganado, en época de lluvias ordeñaban sus vacas y elaboraban panelas que vendían en Los Mochis y Guasave. También extraían sal de los esteros Bacajuzali y Once Ríos para su consumo y venta; el agua dulce que bebían y daban a sus animales estaba disponible todo el año en el arroyo Los Juncos, ubicado entre los ríos Sinaloa y Fuerte, en el norte de Sinaloa.

En junio de 195I se constituyó la Comisión del Río Fuerte (CRF) para impulsar la agricultura de riego en la región, su principal obra fue la presa Miguel Hidalgo y Costilla, construida en la boquilla del Mahone. ${ }^{17}$ La construcción de la presa transformará el paisaje rural y la estructura agraria en el norte de Sinaloa. La CRF terminó la obra en 1956, incluyendo canales, drenes y los caminos necesarios para regar 130,000 ha de las 270,000 programadas, $\frac{18}{2}$ esto inició la colonización del Valle del Fuerte. En el caso del ejido Bachoco, el i6 de agosto de 1955 se publicó 
en el Diario Oficial de la Federación una segunda resolución presidencial, que fue de reacomodo, en la que se reconoció como beneficiarios a diversos grupos de campesinos que venían de otras partes del estado y del país.

El reacomodo

Los campesinos beneficiados en dicha resolución se agruparon de la siguiente manera:

- Grupo "Bachoco", constituido por los vecinos del poblado Bachoco que aparecieron en dos listas, una con 28 beneficiarios de la primera resolución que seguían con vida, y la otra lista con 18 campesinos en donde figuraban sus hijos.

- Grupo "Guasave", integrado por 77 vecinos de la ciudad de Guasave, a quienes el comisionado del Departamento Agrario, ingeniero Cosme Verdura Mier había incluido como beneficiarios en la resolución.

- Grupo "La Presa" formado por un conjunto de 99 campesinos procedentes del Mahone, de los ejidos expropiados de la presa Miguel Hidalgo, y los procedentes de las zonas federales de los cauces del río Fuerte y arroyos tributarios.

- Grupo "Guanajuato", constituido por 97 campesinos miembros del Nuevo Centro de Población Agrícola "San Juan Rancho Viejo", quienes procedían principalmente de los municipios de Acámbaro y Salvatierra, Guanajuato; y de Queréndaro e Indaparapeo, Michoacán.

A la vez que ejecutaba la resolución presidencial, el gobierno había procedido a desmontar con maquinaria y con los propios beneficiarios las tierras del ejido, para enseguida construir los canales para el riego, así como drenes y calles; después mediante sorteo se le asignó una parcela a cada ejidatario. Las unidades de dotación asignadas a cada ejidatario tienen características similares a la propiedad individual, eran inalienables e inembargables además de ser un usufructo que el ejido otorga a los ejidatarios. ${ }^{\text {I9 }}$ Sin embargo, para algunos de los nuevos ejidatarios el ambiente era hostil lo mismo por el intenso calor del verano, que por la abundancia de los bichos y serpientes. El área de $\mathrm{I}_{42}$ ha, asignada como zona urbana, carecía de servicios públicos como energía eléctrica y agua potable. Aunque, la mayoría de los ejidatarios empezó a construir sus humildes casas, aprovechando los horcones y ramas que quedaron en los terrenos desmontados, algunos de los nuevos ejidatarios renunciaron a sus derechos agrarios, reconformando el padrón de ejidatarios, para quedar de la siguiente manera:

Grupo "Bachoco", de los 46 beneficiados, sólo 29 permanecieron en el ejido; el resto, es decir, I7 vivían en la ciudad de Los Mochis y pedían que sus parcelas estuvieran juntas, como las autoridades ejidales no les concedieron esa petición, se molestaron y renunciaron a sus derechos.

Grupo "Guasave", eran 77 beneficiados, de los cuales sólo 53 continuaron; el resto, es decir, 24 no tomaron posesión de su parcela por diferentes motivos, ya que entre ellos había individuos que se encontraban de paso en la ciudad de Guasave, y habían sido enlistados como ejidatarios, pero al saber que tendrían que residir en Bachoco, pidieron ser borrados de la lista, otros ni siquiera se presentaron a la asamblea de parcelamiento. 
Grupo "La Presa", conformado por 99 beneficiados, de los cuales 89 tomaron posesión; los diez restantes optaron por quedarse en el vecino ejido de Las Vacas en donde también eran ejidatarios.

Grupo "Guanajuato", integrado por 97 campesinos beneficiados de los que sólo 2i se quedaron a vivir en Bachoco, los 76 restantes nunca se trasladaron a Bachoco por falta de dinero, a otros no les gustó lo inhóspito del lugar y regresaron a sus lugares de origen, renunciando a sus derechos ejidales.

Al interior del ejido, los integrantes de los grupos: "Bachoco", "Guasave" y "La Presa" se autodenominaron "papariques" y los del grupo "Guanajuato" como "guanajuatos".

El ejido ha regulado el acceso a la tierra mediante un proceso de inclusión y exclusión de distintos grupos sociales, ejecutando la apropiación permanente de ciertas áreas del ejido. ${ }^{20} \mathrm{Al}$ quedar vacantes 127 derechos agrarios, la asamblea general de ejidatarios del 27 de julio de I957 $7^{21}$ instauró el procedimiento que sus ejidatarios adoptarían para apropiarse de su parcela: el desmonte de tierras como requisito para poder ejercer el derecho a tener parcela, por lo que el monte fue cediendo su espacio al trabajo físico que lo iba desplazando, en su lugar se construyeron nuevos linderos y canales. El agua en Bachoco, pasó de ser un recurso sumamente escaso, disponible casi exclusivamente para consumo humano, a ser el transformador de un ejido, que por la calidad de sus tierras, en donde predomina el barrial, se implementarían cultivos sumamente productivos.

El paisaje rural se entiende como la articulación en el tiempo de usos de la tierra y sistemas productivos, esto es, espacios de lucha y de enfrentamientos, construcciones estructuradas desde el poder económico y producto de las luchas de los campesinos. ${ }^{22}$ Los cambios en el paisaje son procesos históricos, realizados en espacios que crean y recrean los actores sociales a partir de las actividades que llevan a cabo,, 3 el gobierno federal fue un gran apoyo para la recreación del espacio por los ejidatarios. En relación con la agricultura, el gobierno federal fijó precios de garantía para, entre otros, los siguientes cultivos: frijol, maíz, trigo, ajonjolí, cártamo, soya, semilla de algodón, sorgo y cebada, ${ }^{24}$ cultivos que en diferentes momentos han sido parte del paisaje rural en Bachoco, a continuación se describen algunas de sus características, precisando que aunque alguno de ellos domina el paisaje en cierto periodo, siempre se han cultivado dos o más en menor proporción.

El arroz (Oriza sativa) se sembró por primera y única vez en 1956, con el sistema de riego por gravedad, por ser un cultivo de alta demanda de agua provocó que muchas parcelas se "ensalitraran", los ejidatarios contaron con el apoyo de la CRF para "lavarlas", quienes con su maquinaria y equipos diseñaron y construyeron drenes agrícolas.

El gobierno federal apoyaba la actividad agrícola facilitando insumos como los fertilizantes, el diesel, el agua, la energía eléctrica, las semillas mejoradas, el crédito y el seguro agrícola mediante subsidios. 25 El crédito de avió para la implementación del arroz, fue otorgado por el Banco Ejidal y administrado en colectivo, es decir, fueron los miembros del Comisariado Ejidal 
(que se constituye con un presidente, un secretario y un tesorero), quienes ejercieron los recursos financieros presupuestados, y en su momento repartieron las utilidades de la cosecha. La cosecha del arroz se realizó con viejas trilladoras que llegaron de fuera, el arroz se encostaló en las parcelas para de ahí llevarlo a los centros de acopio en Los Mochis. Posteriormente, el gobierno federal construyó las bodegas de los Almacenes Nacionales de Deposito S.A. (ANDSA) en Los Mochis, que funcionaron como centros receptores de las cosechas de toda la región. La Comisión Nacional de Subsistencias Populares (CONASUPO) participaba en el mercado de los cultivos que tenían precios de garantía, lo mismo en la cosecha nacional que en su importación, $\underline{26}$ por lo que esta empresa paraestatal compraba y pagaba las cosechas.

En el año de 1957 se sembró trigo (Triticum spp), también fue administrado en colectivo. Esta gramínea fue parte del paisaje rural hasta i990, es un cultivo del ciclo otoño-invierno (O/I) que dejaba buenas ganancias. Después de cosechado el trigo se continuaba con la soya en el ciclo primavera-verano $(\mathrm{P} / \mathrm{V})$, que aumentaba las posibilidades de los ejidatarios de obtener ganancias para satisfacer las necesidades de sus familias.

La ampliación de territorio

El territorio es el espacio apropiado, ocupado y dominado por un grupo social en vista de asegurar su reproducción y satisfacer sus necesidades vitales, que son a la vez materiales y simbólicas. ${ }^{27}$ Es el espacio material del que se pretende excluir o integrar al otro, al poner en acción estrategias para el control de los procesos sociales por parte de ambos grupos y que implican la fijación de la hegemonía $\frac{28}{\mathrm{La}}$ apropiación del espacio, sobre todo, cuando predomina la dimensión cultural, puede engendrar un sentido de pertenencia que adquiere la forma de una relación de esencia afectiva con el territorio. ${ }^{29}$ La tierra y el territorio son garantías de producción y reproducción social de amplios segmentos de la población que se encuentran en el ámbito rural. ${ }^{30}$ Los ejidatarios y pequeños propietarios compiten por el control de la tierra de buena calidad, ${ }^{21}$ en esa competencia participan, en un primer momento, ejidatarios y avecinados de Bachoco, quienes en 1957 tuvieron suficiente dinero como para comprar tierras de propiedad privada que colindaban con el ejido. Las tierras las desmontaron con talachos, hachas, machetes y barras, después las nivelaron con sus tractores, transformandolas de primera calidad. En total fueron 146 ha que se desglosan en el cuadro I.

Cuadro i. La primera ampliación del territorio

\begin{tabular}{|l|c|c|}
\hline \multicolumn{1}{|c|}{ Comprador } & Cantidad & Predio \\
\hline Armando Estrada Solís & Io & San Pedro de Los Batequis \\
\hline Teódulo Estrada Acevedo & 36 & San Pedro de Los Batequis \\
\hline Silverio Estrada Acevedo & Io & San Pedro de Los Batequis \\
\hline
\end{tabular}




\begin{tabular}{|l|c|c|}
\hline Leonel Estrada Solís & 50 & San Pedro de Los Batequis \\
\hline $\begin{array}{l}\text { Cuauhtémoc y Juan Estrada } \\
\text { Huijón }\end{array}$ & 40 & San Pedro de Los Batequis \\
\hline TOTAL & I46 & \\
\hline
\end{tabular}

Fuente: elaboración propia a partir de informantes clave.

Estas compras reflejan el aumento del territorio, concebido como un espacio productivo en construcción que, con el tiempo, se transformó en factor de identidad (con una suerte de rasgo de doble identidad, ya que los dueños de las tierras eran pequeños propietarios y ejidatarios) dado que los límites entre el ejido y el predio son más formales que reales. No así en el proceso productivo, como ejidatarios se debían organizar en sociedades de crédito.

Las sociedades de producción rural son figuras asociativas reglamentadas por la Ley General de Crédito Rural de i976. Su antecedente son las sociedades locales de crédito agrícola reglamentadas por la Ley General de Crédito Agrícola de i955. ${ }^{32}$ Durante los años de 1956 y i957, los ejidatarios sembraron en colectivo, enseguida por afinidad formaron sociedades de crédito ejidal, donde un socio delegado era el responsable de tramitar el crédito ante el Banco de Crédito Ejidal sucursal "B" Juan José Ríos, ubicado en el poblado de Juan José Ríos. A las sociedades también se les otorgaban créditos refaccionarios para la compra de tractores equipados y de trilladoras. Cuando por siniestros como las heladas, ciclones o plagas, el ejidatario no podía cubrir el importe del crédito de avío, la Aseguradora Nacional Agrícola y Ganadera (ANAGSA) cubría dicho crédito. Si el ejidatario no podía pagar por mala administración a sus socios, el banco les aplicaba de manera proporcional los descuentos para cubrir el adeudo, para que siguieran sembrando.

El cártamo (Carthamus tinctorius) fue un cultivo que durante muchos años se implementó en el ciclo O/I; no requería de labores culturales, se fertilizaba y con sólo un riego de auxilio era suficiente para su desarrollo y de ahí a la cosecha. Dejaba buenas ganancias sin mucha inversión, además de que limpiaba las parcelas de malezas como el pasto Johnson.

La flor de cempoal (Tagetes erecta), se incentivó desde inicios hasta fines de los ochenta, para su implementación se hacían contratos entre los ejidatarios y las compañías deshidratadoras que compraban la cosecha. La recolección de la flor se realizaba con mano de obra en los primeros años, y después con modernas máquinas. La producción que se obtenía era muy buena, fluctuaba de 20 hasta 30 toneladas por hectárea y dejaba buenos márgenes de utilidad. La flor dejó de cultivarse debido a que las compañías deshidratadoras cambiaron la variedad "Hawái" por otras variedades menos productivas, pero que reportaban más beneficios a las empresas por la calidad de sus pigmentos. 
El frijol (Phaseolus vulgaris) empezó a ser una buena opción desde inicios de los setenta, se siembra en el ciclo O/I, genera lo mismo buenas ganancias que pérdidas. En las tierras del ejido se producen hasta 3 toneladas por hectárea, si se logra cosechar en la segunda quincena de febrero, se puede sembrar sorgo "tempranero" en el ciclo $\mathrm{P} / \mathrm{V}$ que no se ve afectado por las plagas, que posibilita buenas ganancias en ambos cultivos.

El algodón (Gossypium hirsutum) se sembró desde 1965 hasta 1989, fue muy redituable económicamente, además de generar empleos por las labores que requería, como el deshije o aclareo, los deshierbes, los aporques, las fumigaciones y entre cuatro a cinco riegos, así como la pizca. Su periodo iniciaba de mediados de noviembre a diciembre, la pizca se efectuaba de junio a julio, con mano de obra que venía de otros estados de la república y de la región. La mano de obra era alojada en galerones ubicados en el poblado, que vivía una zafra de 45 a 60 días. El algodón era redituable, con una buena cosecha los ejidatarios podían comprar un tractor equipado o bien construir su casa de material substituyendo la de madera. Las plagas y el bajo precio de la fibra hicieron que pasara a la historia.

Bachoco fue parte de una ruta migratoria de jornaleros agrícolas de Zacatecas, Guanajuato, Michoacán, Coahuila, Oaxaca, Nayarit y Sonora, quienes venían de la pizca de algodón de la región de La Laguna. En Sinaloa llegaban al Valle de Culiacán, donde comenzaban las pizcas en el mes de junio, de ahí continuaban en el Valle del Fuerte donde se pizcaba desde fines de junio hasta julio, para seguir a los Valles del Mayo y del Yaqui en Sonora en agosto, finalizando en el Valle de Mexicali, Baja California, en el mes de septiembre.

La recolección del algodón requería de mucha mano de obra, y se disponía de poco tiempo, porque si empezaban las lluvias la fibra se manchaba y disminuía su precio, por lo que los ejidatarios garantizaban albergue a los trabajadores construyendo galerones, aunque algunos ejidatarios, para asegurar aún más la mano de obra, aceptaban a los trabajadores y sus familias, construyendo albergues en su solar para que ahí se alojaran, en ocasiones, la relación trabajadorejidatario se profundizaba y los jornaleros se quedaban a vivir en Bachoco trabajando en otras labores como los deshierbes y riegos de la soya. Con el tiempo, algunos trabajadores quisieron ser ejidatarios, los requisitos eran mínimos: ser mexicano, mayor de edad, o bien tener familia a su cargo, anotarse y estar al corriente de las cuotas que se aportaban al Comité Ejecutivo Particular del NCPE demandante de tierras. Por lo que aprovecharon la oportunidad de ser agraristas, y junto con otros solicitantes fueron parte de las luchas que modificaron la estructura agraria en Sinaloa.

El territorio es un espacio privilegiado para estudiar la relación entre las luchas sociales y el desarrollo rural, donde se concretizan las relaciones de poder y los conflictos entre los actores que posibilitan o limitan la construcción del desarrollo. ${ }^{33}$ La lucha por la tierra en la que jornaleros agrícolas, hijos de ejidatarios y avecinados de Bachoco participaron tuvo resultados diferenciados, algunos de ellos son ejidatarios con tierras de primera calidad de riego, otros tienen tierras de temporal, unos pocos cuentan con tierras para la acuicultura, y al resto les quedó la experiencia de su participación en la invasión de predios. 
La invasión de predios agrícolas era parte de un proceso de lucha por la tierra, donde el grupo solicitante de tierras presionaba a las autoridades agrarias buscando una resolución favorable a sus demandas, para ello se trasladaban al centro del predio solicitado, donde construían sus humildes casas de lámina de cartón negro, instalando en el centro de la invasión una bandera nacional, como símbolo de mexicanidad y protección contra el desalojo y la violencia del ejército. El ejército y las policías municipal y judicial del estado muchas veces desalojaban la invasión mediante la fuerza, en otras ocasiones el grupo solicitante resultaba favorecido. El resultado de las luchas agrarias fue la recomposición del espacio y de una apropiación de clase social distinta, con una mayor influencia de los ejidatarios; de la que los campesinos relacionados con Bachoco son buen ejemplo, como se puede demostrar en el cuadro 2.

Cuadro 2. La ampliación del territorio en otros ejidos

\begin{tabular}{|c|c|c|c|c|c|}
\hline Ejido & Municipio & Ejidatarios & Hectáreas & $A \tilde{n} o$ & Sistema \\
\hline Francisco I Madero & Angostura & 5 & 50 & 1962 & Riego \\
\hline S. Lerdo de Tejada & Angostura & 20 & 200 & 1962 & Riego \\
\hline Bachoco II & Ahome & 42 & 470 & 1965 & Riego \\
\hline Bachomobampo & Ahome & 5 & $5^{\circ}$ & 1966 & Riego \\
\hline San Ignacio & Sinaloa & 80 & 800 & 1967 & Temporal \\
\hline Tobobampo & Sinaloa & 3 & 30 & 1967 & Riego \\
\hline San Bruno & Sinaloa & 3 & 30 & 1972 & Temporal \\
\hline El Cabezón & Sinaloa & I & IO & 1972 & Temporal \\
\hline La Cuestona & Sinaloa & 4 & 40 & 1972 & Temporal \\
\hline Campo El Tajito & Guasave & 3 & 30 & 1976 & Riego \\
\hline Cruz Blanca & S. Alvarado & 3 & I4 & 1979 & Riego \\
\hline Chorohui & Guasave & 5 & 27 & 1980 & Riego \\
\hline Cerro Cabezón II & Ahome & II & 700 & 1987 & Marismas \\
\hline
\end{tabular}




\begin{tabular}{|l|l|l|l|l|l|}
\hline TOTAL & I85 & $2,45 \mathrm{I}$ & & \\
\hline
\end{tabular}

Fuente: elaboración propia a partir de informantes clave.

El cuadro 2 refleja que i85 campesinos, en su mayoría originarios del estado de Guanajuato, se adaptaron al marco legal que el Estado y las circunstancias impusieron, y realizaron su sueño de ser ejidatarios, al ser parte de algún ejido. Bachoco se constituyó en un puente entre los campesinos que emigraban de Guanajuato a Sinaloa buscando ser ejidatarios, y encontraban en su gente la solidaridad, la información que era proporcionada a la hora de la comida, cuando andaban trabajando o bien en los ratos de ocio cuando coincidían en el billar, en estos lugares les informaban con quién y en qué momento había que dirigirse para pedir ser parte del grupo solicitante, y los compromisos que estaban obligados a cumplir, como asistir a las juntas, aportar las cuotas para el sostenimiento de los líderes cuando iban a Culiacán o a la Ciudad de México y, de ser necesario, participar activamente en la invasión de predios agrícolas.

El inicio de la definición de un territorio de influencia por parte de los ejidatarios de Bachoco fue por medio de la construcción de un paisaje agrícola uniforme, especialmente con la siembra de algodón, y producto de una tradición de lucha agraria. El ejido se consolida territorialmente mediante el desarrollo de la producción especializada y, sobre todo, en la obtención de tierras más allá del municipio de Guasave, en ejidos de los municipios de Angostura, Ahome y Sinaloa y, con ello, del establecimiento de una red de relaciones familiares y políticas que al reproducirse consolidaran en esta parte del norte del estado la idea de que los denominados "bachoqueños" son solidarios entre sí, trabajadores, y capaces de luchar por la tierra contra los latifundistas.

En el contexto de las afectaciones y expropiación de latifundios que realizó el presidente Luis Echeverría Álvarez, en los valles agrícolas del Yaqui y Mayo en Sonora, y del Fuerte y Culiacán en Sinaloa, las familias Peña Rivas y Peña Farber pusieron a disposición de la SRA 234 ha, que por confusión con un ejido denominado Bachoco del municipio de Culiacán, que solicitaba ampliación, le fueron otorgadas al ejido Bachoco, Guasave, como ampliación.

La ampliación ejidal llegó de improviso, provocando que los hijos de ejidatarios menores de I8 años y sin familia a su cargo se casaran, para así cumplir con los requisitos que exigía la ley agraria en vigor. Se anotaron ante las autoridades ejidales poco más de ochenta solicitantes. Los integrantes de la ampliación trabajaron las tierras en colectivo, siendo administrados los recursos financieros por la autoridad ejidal, el reparto de las ganancias era equitativo. Tras un proceso de depuración, donde se valoró quienes realmente cumplían con todos los requisitos, quedaron 46 ejidatarios con parcelas de 3.5 a 8 ha, dependiendo de la calidad y ubicación de la tierra.

La ampliación ejidal significó tanto la disputa por la tierra entre los hijos de los ejidatarios entre sí, como la propia ampliación del territorio, afectando a agricultores tradicionales dedicados a la horticultura. 
Algunas hortalizas como el tomate (Solanum lycopersicum) se sembraron en Bachoco, primero en asociación (a "medias" de utilidades y de costos de producción con los dueños de los empaques), o bien mediante el arrendamiento de la parcela, durante el ciclo vegetativo del tomate, la recolección y en la venta; la participación del ejidatario se limitaba al rol de observador.

Al terminar la cosecha del tomate de exportación, los ejidatarios se trasladaban a la ciudad de Nogales, Sonora, donde tenían que aceptar los costos de producción y administración que el dueño del empaque les presentaba. En ocasiones obtenían buenas ganancias y en otras había pérdidas, dado que el precio del tomate lo fijan las fluctuaciones del mercado estadounidense. El tomate tuvo su auge de 1975 hasta 1984 aproximadamente, su fuente de financiamiento eran compañías agrícolas estadounidenses que transferían los recursos a los empresarios mexicanos, quienes se asociaban con los ejidatarios.

La sandía (Citrullus lanatus) fue un cultivo que se implementó en 1972, inicialmente fue a "medias", poco después en arrendamiento, dadas las buenas condiciones del suelo. Hubo ciclos agrícolas en que se sembraron hasta poco más de mil hectáreas.

El financiamiento era similar al del tomate. Sin embargo, con la sandía se generaron conocimientos y experiencia en los ejidatarios, aquellos que se capitalizaron empezaron a sembrarla por su cuenta, hasta que la presencia de un hongo volvió poco redituable este cultivo y desapareció del paisaje.

Para los ejidatarios que implementaron este cultivo hubo cambios en la percepción de su rol, ya que sembrar una hortaliza como lo hacían los agricultores del sector privado, aunado a las exigencias de un mercado sumamente dinámico como el estadounidense, requirió que fueran más dinámicos y audaces que sus compañeros. El precio de la sandía fluctuaba de acuerdo al mercado estadounidense, la semilla no podía comprarse en el mercado local, los agroquímicos eran caros, era necesaria la relación con los introductores para el crédito y no se aseguraba el cultivo, es decir, era una actividad sumamente riesgosa.

La relación con gerentes de bancos y agroindustrias, permitió a algunos ejidatarios ricos de Bachoco conocer del quebranto económico de neolatifundistas, quienes estaban en cartera vencida y vendían sus tierras a precios por debajo del valor comercial, expandiendo con estas adquisiciones el territorio en varios predios del Valle del Fuerte, como se describe en el cuadro 3.

Cuadro 3. La expansión en el Valle del Fuerte

\begin{tabular}{|l|l|c|l|}
\hline \multicolumn{1}{|c|}{ Ejidatario } & Predio & Hectáreas & \multicolumn{1}{|c|}{ Año } \\
\hline Efraín Flores García & Vinoramas & 45 & 1978 \\
\hline
\end{tabular}




\begin{tabular}{|l|l|c|l|}
\hline Efraín Flores García & Corerepe & 20 & I99I \\
\hline Efraín Flores García & Jesús María & 39 & I992 \\
\hline Jesús y Efraín Flores García & Los Natochis & 90 & I980 \\
\hline Félix Carrillo Ramírez & Corerepe & I75 & I980/8I \\
\hline Filemón Flores García & Saratajoa & 29 & I978/80 \\
\hline Gregorio Inzunza Castro & Corerepe & 20 & I980 \\
\hline Gregorio Inzunza Castro & Tetameche & 55 & I990 \\
\hline José Cruz Becerra & Corerepe & IO & I98I \\
\hline José Luis Moreno Heredia & Corerepe & IO & I98I \\
\hline Jesús Becerra Piña & Corerepe & I2 & I98 I \\
\hline José Heredia Estrada & Corerepe & $726 / 87$ \\
\hline Ezequiel Herrera Lule & & & \\
\hline
\end{tabular}

Fuente: elaboración propia a partir de informantes clave.

En el cuadro 3 se observa como en una década se expandió el territorio, proceso en el que participaron ejidatarios y vecinos de Bachoco adquiriendo propiedades de predios del Valle del Fuerte, consolidando así una identidad de ejidatarios trabajadores y dinámicos.

Los productores agrícolas enfrentarían una situación inédita en el campo, una serie de reformas legales que desde el poder ejecutivo federal modificaran su relación con el campo mexicano.

\section{Las reformas neoliberales}

Las reformas neoliberales incluyeron el ingreso de México al Acuerdo General sobre Aranceles Aduaneros y Comercio (GATT). Después de ser una economía cerrada, en muy poco tiempo de I986 a I988, se realizó un profundo proceso de apertura comercial, 34 la apertura significó para 
los ejidatarios de Bachoco que cuando iban a realizar su cosecha de trigo, se informaban de que por los puertos de Topolobampo y Mazatlán llegaba trigo de los Estados Unidos, de igual forma pasaba con la soya aunque en este caso era pasta de soya lo que se importaba. Los dueños de las agroindustrias preferían importar granos y pasta de soya porque eran más baratos.

El gobierno federal eliminó los precios de garantía, además de que la CONASUPO restringió sus compras, lo que agravó la comercialización de las cosechas tradicionales, cuyo espacio fue ocupado por el maíz que, desde 1992 hasta la fecha, es el cultivo que predomina. Dado que su ciclo vegetativo es largo, se siembra como único cultivo en el ciclo O/I, o bien como segundo en el ciclo P/V. En el ciclo O/I su producción por hectárea es de ir a I5 toneladas por hectárea; en el ciclo $\mathrm{P} / \mathrm{V}$ fluctúa de 8 a in toneladas por hectárea. Este cultivo requiere pocos trabajos, sólo se fertiliza y aporca, se le suministran de 4 a 5 riegos, por lo que prácticamente no genera empleos.

El último periodo de compra de tierras privadas, por ejidatarios de Bachoco, fue en I996, cuando el maíz dejó muchas ganancias, ya que alcanzó un precio de \$1,850 por tonelada y hubo producciones de io a is toneladas por hectárea, quienes habían sembrado maíz pudieron comprar tierras. En el cuadro 4 se desglosan dichas compras.

Cuadro 4. La última ampliación del territorio

\begin{tabular}{|l|l|l|l|}
\hline \multicolumn{1}{|c|}{ Ejidatario } & \multicolumn{1}{|c|}{ Predio } & \multicolumn{1}{|c|}{ Cantidad } & \multicolumn{1}{|c|}{} \\
\hline Maximiliano Flores A. & Santa María & 40 & 1996 \\
\hline Efraín Flores García & Santa María & 40 & 1996 \\
\hline Jesús Flores García & Santa María & 40 & 1996 \\
\hline Miguel López & Corerepe & I0 & 1996 \\
\hline Gelasio Peña Jiménez & Corerepe & 30 & 1996 \\
\hline Salud Sierra Rosillo & Corerepe & 40 & 1996 \\
\hline Salud Sierra Rosillo & Corerepe & 60 & \\
\hline TOTAL & & 260 & \\
\hline
\end{tabular}

Fuente: elaboración propia a partir de informantes clave.

El cuadro 4 refleja que fue posible la construcción de un tipo de ejidatario capaz de desplazar a algunos elementos de la vieja burguesía agraria que existía en el estado. Todas estas 
adquisiciones, y la ubicación de los predios en el Valle del Fuerte en donde predominan los grandes agricultores, lograron la expansión del territorio de Bachoco y la consolidación de una fama de ejidatarios trabajadores.

La implementación, en enero de 1995 , del programa de certificación de derechos ejidales y titulación de solares urbanos (PROCEDE) reveló que en Bachoco existían 45I ejidatarios, una parcela ejidal, las parcelas de las escuelas primarias Benito Juárez y Nicolás Bravo. ${ }^{35}$ Así mismo, los 45 I ejidatarios poseen un total 4,057-27-0o ha. Respecto de la titulación de los solares urbanos, la Secretaría de Desarrollo Agrario Territorial y Urbano inició en mayo de 2018 el proceso de regularización.

Actualmente existen 496 ejidatarios, a los que podemos clasificar y establecer una tipología, de acuerdo con la cantidad y calidad de sus tierras, la maquinaria agrícola con que cuentan, el tipo de cultivos que siembran, los créditos de que disponen y los costos de producción de sus cultivos.

\section{Los tipos de ejidatarios}

Ejidatarios Empresarios, este grupo de ejidatarios está constituido por 45 productores. En relación con la tierra, destacan los siguientes rasgos: siembran de 20 hectáreas en adelante de tierras de buena calidad, han comprado parcelas ejidales, sobre todo, después de las reformas al artículo 27 constitucional, además de terrenos de propiedad privada.

Cuentan con crédito de la banca privada o de la financiera rural, operan en sociedades de producción rural integradas por sus familiares, lo que les asegura el cumplimiento del pago de los créditos, ya que ponen como aval ante los bancos sus escrituras y facturas de tractores y camionetas. Para ellos no es mayor problema que la ministración del crédito se retrase hasta los meses de noviembre o diciembre, ya que la mayoría disponen de dinero suficiente como para sufragar los gastos que originan las labores de preparación, el pago del agua para riego y la compra de otros insumos.

En cuanto a la maquinaria agrícola, la mayoría tiene dos o más tractores con equipo de labranza moderna: sembradoras de precisión, cultivadoras y fertilizadoras, algunos cuentan con máquinas trilladoras y camiones para la recolección y el traslado de las cosechas, dos familias tienen, cada una, una empresa de venta de fertilizantes.

El tipo de cultivos que siembran es amplio y dentro de las hortalizas predominan el tomate saladette (Solanum lycopersicum), chile Anaheim (Capsicum annumm l.) y chile serrano (Capsicum annumm cv). Aunque por estrategia también siembran granos como el maíz y el frijol, de esa manera, si tienen pérdidas en las hortalizas, con las ganancias de los granos compensan las pérdidas de las hortalizas. Cuando tienen buenas ganancias en las hortalizas son los que influyen para que aumente el costo del arrendamiento de las parcelas, ya que se vuelve más intensa la disputa por las mejores tierras que al final se quedan con quien paga más. En el cultivo de granos son capaces de disminuir los costos de producción, ya que compran las semillas, los agroquímicos y los fertilizantes al mayoreo y consiguen así mejores precios. 
Los ejidatarios empresarios buscan determinar quiénes deben ser las autoridades ejidales, por lo que acuden a las asambleas electivas, cuando lo logran tratan de evitar pagar las cuotas que la asamblea ha establecido por el arrendamiento y venta de parcelas ejidales. También, en términos del poder regional, han logrado establecer relaciones políticas y sociales con dirigentes de organizaciones como la Asociación de Agricultores del Río Sinaloa Poniente (AARSP), filial de la Confederación de Asociaciones Agrícolas del Estado de Sinaloa (CAADES), lo que les permite tener facilidades para obtener paquetes crediticios de programas gubernamentales, para la compra de maquinaria agrícola, la nivelación y el mejoramiento de sus tierras.

Ejidatarios Campesinos, este grupo está constituido por 2or elementos. En relación con la tierra, la mayoría siembran sólo su parcela, aunque algunos puedan arrendar una o dos parcelas más, dependiendo de la calidad de la tierra y del costo del arrendamiento, en este sentido, se ven afectados en la cantidad de tierra que siembran cuando se incrementa mucho el costo del arrendamiento.

En cuanto al crédito, la mayoría opera créditos refaccionarios y de avío con la financiera rural. Los cultivos que más siembran son granos como el maíz, frijol y sorgo, pero también pequeñas cantidades de hortalizas como tomate saladette.

Respecto de la maquinaria, la mayoría sólo tiene un tractor, algunos tienen dos que pueden ser modernos o de medio uso, en general, no cuentan con todos los equipos necesarios por lo que se prestan entre sí dichos equipos, o bien solicitan que algunas labores como la siembra sea maquilada con sembradoras de precisión de los ejidatarios empresarios, con los que, en general, tienen buena relación, a pesar de que compiten por el arrendamiento de parcelas de ejidatarios. En cuanto a los costos de producción, algunos logran pequeños ahorros, ya que ellos mismos hacen ciertas labores como la preparación, los riegos y aporques.

Este tipo de ejidatarios son los que más acuden a las asambleas del ejido, por lo que es el más representativo del ejido, tanto por su número como por su participación en demandas por mejores precios a las cosechas.

Ejidatarios Arrendadores, I29 ejidatarios se caracterizan por arrendar sus parcelas, no tienen crédito ni maquinaria agrícola para realizar los trabajos. La mayoría tiene tierra de buena calidad, por lo que los arrendatarios ya les han abonado por adelantado el pago de uno o dos ciclos agrícolas. Los pocos casos en que un ejidatario arrendador ha vuelto a sembrar su parcela son porque ha recibido apoyo económico de sus familiares, hijos o hermanos que están en Estados Unidos.

La mayoría trabaja con los ejidatarios campesinos o empresarios a los que rentan su parcela, en trabajos de cierta especialización como tractoristas o en los riegos, otros son pensionados del Instituto Mexicano del Seguro Social, algunos han emigrado a los Estados Unidos. Su participación en las asambleas de ejidatarios se concreta a aquellas en que se elige autoridades ejidales, donde votan a favor de la planilla que impulsan los ejidatarios que han arrendado su parcela. 
Ejidatarios Minifundistas Campesinos, este grupo está integrado por 99 ejidatarios que tienen parcelas cuya extensión va desde media hasta cinco y media hectáreas. En general, los campesinos minifundistas se caracterizan por tener tierras de mala calidad, desniveladas y colindando con los esteros, por lo que sus esfuerzos para hacer producir sus parcelas es mayor. En esta categoría se incluye a quienes han comprado desde una a cinco hectáreas, estas compras han sido paulatinas, en un año compran una hectárea a un amigo o familiar, uno o dos años después otra y así sucesivamente, estas compras se formalizan ante notario público con el carácter de arrendamiento por cincuenta años.

La mayoría de estos ejidatarios carecen de crédito agrícola, algunos son trabajadores de los ejidatarios campesinos o empresarios, como tractoristas, regadores $u$ otras actividades; generalmente, sus patrones les prestan la maquinaria y a través de ellos consiguen la semilla y el fertilizante que pagan hasta que cosechan.

Ejidatarios Minifundistas Arrendadores, este grupo de 28 ejidatarios, a los que no les alcanza el dinero que obtienen de la renta para vivir, por lo que se tienen que dedicar a otras labores ya sea como albañiles o jornaleros agrícolas. La mayoría rentan su parcela porque carecen de crédito de avío y de maquinaria agrícola para realizar las labores culturales.

Ejidatarios Formales, 45 individuos que carecen de parcela porque ya la vendieron, pero tienen un certificado de derechos parcelarios en donde se estipula que tienen derechos proporcionales de las tierras de uso común, que en este ejido son 762 hectáreas de marismas y tierra salitrosa, su vinculación con los problemas del ejido y el resto de ejidatarios se reduce a su participación en las asambleas ejidales cuando se elige el comisariado ejidal.

\section{Conclusiones}

En su lucha para acceder a la tierra, los campesinos del ejido Bachoco lograron construir diversos mecanismos a través de los cuales desplegaron una especial capacidad, para adaptarse al marco legal que el Estado mexicano estableció en las diferentes legislaciones agrarias, en ese sentido el reacomodo de campesinos solicitantes de tierra y los desplazados de la presa Miguel Hidalgo y Costilla, así como el desmonte y parcelamiento de las tierras significó para los nuevos ejidatarios empezar a sembrar cultivos que demandaba el Estado.

Los campesinos de Bachoco han tenido la capacidad para adaptarse, y seguir siendo ejidatarios, a pesar de los cambios en el paisaje rural que primero el Estado y después el mercado lograron imponer. Esos cambios se tradujeron en conocimientos sobre diferentes tipos de cultivo, desde granos hasta hortalizas, así como también en su inclusión en las diversas formas organizativas para sembrar, como las sociedades de crédito ejidal, las sociedades de producción rural, o bien con crédito individual. En cuanto a lo productivo, a inicios de los ochenta se dan cambios en el paisaje, en los que el predominio del cultivo del algodón disminuye por las drásticas caídas del precio mundial de la fibra, aunque se dan repuntes esporádicos como el que ocurrió en el ciclo agrícola 1986/1987. Ante dicha situación los ejidatarios buscaron otras opciones como los cultivos de trigo, soya, frijol, sorgo, cempoal y cártamo, aunque desde 
mediados de los ochenta, las cosechas de trigo, soya y cártamo enfrentaron problemas de comercialización por la apertura comercial que ocasionó el ingreso de México al GATT.

Los ejidatarios de Bachoco fueron capaces de adaptarse al momento histórico en su lucha por la tierra, con las condiciones que el Estado mexicano implementó, lo que permitió la ampliación de un territorio agrario propio, más allá del ejido, en las regiones norte y centro-norte del estado de Sinaloa, la conservación o ampliación del actual territorio agrario de Bachoco exige de sus ejidatarios, en estos momentos, un mayor esfuerzo del que se desplegó cuando lo extendieron, el Estado ya no es su aliado, en el Artículo 27 constitucional se derogó el reparto agrario.

Los jornaleros agrícolas e hijos de ejidatarios de Bachoco que lucharon por acceder a la tierra, se asentaron en I2 ejidos en donde I74 ejidatarios poseen I,75I-OO-oo ha en explotación, así mismo, in ejidatarios cuentan con 700 hectáreas de terreno acuícola. Aunque el reparto agrario se haya finiquitado desde las reformas al Artículo 27 de la Constitución, esta vía, especialmente practicada a través de las tomas de tierra, marcó el espíritu de los de Bachoco, representando parte de la memoria colectiva y del territorio extenso del ejido. Así mismo, los ejidatarios de Bachoco, se pusieron de acuerdo, a pesar de las diferencias internas para distribuir 234 ha de la ampliación, lo que por un lado demuestra un fuerte sentido patrimonial de pertenencia en torno a la tierra y, por otro, el carácter expansivo y dominante del ejido en la región.

Los ejidatarios bien posicionados económicamente pudieron disputar a los agricultores la compra de las mejores tierras, con la obtención de 978 ha de primera calidad bien ubicadas. Tanto por el punto anterior como por la compra de tierras en la forma de propiedad privada prevalece un sentido de identidad hacia Bachoco y fortalece la red de grupos que componen esta comunidad en el despliegue del "territorio extenso".

Aunque todos los ejidatarios de Bachoco en un principio fueron del tipo campesino, se empezó a dar una diferenciación entre ellos a fines de los setenta, cuando ya no sólo se sembraron en el ejido granos básicos y algodón, sino que también comenzaron a sembrarse hortalizas a "medias" entre empresarios agrícolas y ejidatarios; algunos de estos últimos, a los que les fue bien, transitaron de ejidatarios campesinos a ejidatarios empresarios. Con la siembra de hortalizas también empezó a darse el arrendamiento de grandes extensiones y con ello se generó otro tipo de ejidatario: el "rentador". La posesión pacífica de tierras y la ampliación del ejido habrían de originar otros dos tipos de ejidatario: el ejidatario minifundista campesino y el ejidatario minifundista arrendador. Los cinco tipos de ejidatarios participan en la disputa por un recurso sumamente limitado: la tierra de buena calidad. Los ejidatarios que han vendido su parcela pero conservan su certificado de derechos parcelarios forman el último grupo: los ejidatarios formales.

Los ejidatarios empresarios pretenden desde antes de las reformas al Artículo 27, comprar y rentar la mayor cantidad de tierra en el ejido, para lograrlo ofrecen buenos precios y disponibilidad inmediata de dinero. 
Los ejidatarios campesinos buscan reproducir su familia y heredar la parcela a los hijos, si tienen buena cosecha están en condiciones de comprar o rentar una parcela, ven con recelo que las compraventas de parcelas sean muy sencillas y que escapen al control de los órganos de discusión, resolución y dirección del ejido como son la Asamblea General de Ejidatarios y el Comisariado Ejidal. La vocación por la tierra de este último tipo de ejidatarios hace que sean solidarios entre sí, a la vez que ubican como potencial adversario en su disputa por la tierra a los ejidatarios empresarios.

Los ejidatarios minifundistas campesinos, cuya principal aspiración es seguir siendo campesinos y para ello buscan completar sus diez hectáreas, son aliados naturales de los ejidatarios campesinos para tratar de controlar el mercado de tierras en el ejido. Los ejidatarios arrendadores y minifundistas arrendadores son considerados los que tienen más probabilidades de vender la parcela ya sea en uno o en varios pagos. Los ejidatarios formales que vendieron su parcela, difícilmente volverán a realizar actividades productivas en terreno propio.

Finalmente, puedo afirmar que los ejidatarios de Bachoco han logrado producir en condiciones económicamente favorables o desfavorables. Esto ha sido posible gracias al esfuerzo en el ejido, y hacia su territorio de influencia, con diversas formas de organización productiva, lo que ha permitido mantener el ejido, cuyas tierras en explotación suman 4,057-27-0o ha, en un marco de cambios económicos, sociales y políticos vertiginosos y, en general, desfavorables para los ejidatarios. En este sentido, este ejido se encuentra fuera de la media regional y nacional, donde la mayoría de las tierras ejidales de buena calidad están rentadas o han sido vendidas.

\section{Documentos}

Carpeta básica del ejido Bachoco, enero de 1973.

Acta de la asamblea ejidal de Bachoco del 27 de julio de 1957.

Acta del PROCEDE del ejido Bachoco, Guasave, Sinaloa, 8 de enero de i995.

Bibliografía

ABOITES AGUILAR, Luis. Cuentas del reparto agrario norteño 1920-1940. México: Ciesas, Cuadernos de la Casa Chata, i988.

CARTON DE GRAMMONT, Hubert. "La presencia norteamericana en el agro sinaloense de la primera mitad del siglo XX". Secuencia Revista de Historia y Ciencias Sociales (7) (I987): 2I.

Los empresarios agrícolas y el Estado. México: Instituto de Investigaciones SocialesUniversidad Nacional Autónoma de México, I990, I42-I43.

CONCHEIRO BÓRQUEZ, Luciano. "Conceptualización del mercado de tierras: una perspectiva campesina". En Mercado de tierras en México, coord. Luciano Concheiro Bórquez, I60-I83. Roma: FAO, I995. 
CONCHEIRO BÓRQUEZ, Luciano y Roberto DIEGO QUINTANA. "Mercado de tierras en los 'tiempos del cólera. Campesinos, tierra y neoliberalismo en México"'. En Propiedad y organización rural en el México moderno, coord. Julio Moguel, I55. México: Juan Pablos Editor, 1998.

ESCOBAR OHMSTEDE, Antonio. "Cambios en el paisaje hidroagrario. ¿La revolución un detonante?: el caso de San Luis Potosí (1910-1940)". Relaciones Estudios de Historia y Sociedad XXXIV(136) (2013): 267.

GUÍZAR VÁZQUEZ, Francisco. "Estrategias de apropiación territorial y de construcción de hegemonía en un contexto intergrupal: el caso de San Lucas Jalpa, El Mezquital Durango". Relaciones Estudios de Historia y Sociedad XXVI(IоI) (2005): 90.

GUZMÁN GÓMEZ, Elsa. "Alimentación, soberanía y agricultura campesina”. En Agriculturas campesinas en Latinoamérica propuestas y desafíos, ed. Francisco Hidalgo, François Houtart y Pilar Lizárraga, 224. Quito: CLACSO, Foro Mundial de Alternativas, Instituto de Altos Estudios Nacionales, La Universidad del Posgrado del Estado, 2014.

ISAAC-MÁRQUEZ, Ricardo et al. "Programas gubernamentales y respuestas campesinas en el uso del suelo: el caso de la zona oriente de Tabasco". Región y Sociedad XX (43) (2008): 99.

ROBLES BERLANGA, Héctor y Luciano CONCHEIRO BÓRQUEZ. "Vigencia de la reforma agraria en América Latina”. En Agriculturas campesinas en Latinoamérica propuestas y desafíos, ed. Francisco Hidalgo, François Houtart y Pilar Lizárraga, iı6. Quito: CLACSO, Foro Mundial de Alternativas, Instituto de Altos Estudios Nacionales, La Universidad del Posgrado del Estado, 20I4.

RODRÍGUEZ WALLENIUS, Carlos et al. "Escudriñar los enfoques teóricos sobre territorio". En Defensa comunitaria del territorio en la zona central de México. Enfoques teóricos y análisis de experiencias, coord. Carlos Rodríguez, 27-28. México: Juan Pablos Editor, 2010.

ROMERO-IBARRA, María Eugenia. "La reforma agraria de Cárdenas y la industria azucarera de México, 1930-1960". Historia Agraria (52) (2010): ir6.

SHANIN, Teodor. Naturaleza y lógica de la economía campesina. Barcelona: Anagrama I976, 8-9.

SOSA VELÁSQUEZ, Mario. "El acaparamiento de tierras y territorios: determinante para la agricultura familiar en América Latina". En Agriculturas campesinas en Latinoamérica propuestas y desafíos, ed. Francisco Hidalgo, François Houtart y Pilar Lizárraga, 87. Quito: CLACSO, Foro Mundial de Alternativas, Instituto de Altos Estudios Nacionales, La Universidad del Posgrado del Estado, 20I4.

TORREgroSA, María Luisa. Agua y riego. Desregulación de la agricultura en México. México: Flacso México, 2009, 60, 67, 68, 9I. 
TORRES-MAZUARA, Gabriela. "El ejido posrevolucionario: de forma de tenencia sui generis a forma de tenencia ad hoc". Península VII(2) (20I2): 76, 82, 85 .

. "La flexibilidad y rigidez del ejido como forma de tenencia de la tierra". Relaciones Estudios de Historia y Sociedad XXXV (I39) (2014): 257, 266, 277.

WARMAN, Arturo. "Notas para una redefinición de la comunidad agraria". Revista Mexicana de Sociología, año 47(3) (julio-septiembre i985): 7.

Notas

I Este trabajo es producto parcial de la "tesis dinámica del mercado de tierras del ejido Bachoco, Guasave, Sinaloa". Realizada con beca del Conacyt, en la Maestría en Desarrollo Rural de la Universidad Autónoma Metropolitana Unidad Xochimilco.

2 Gabriela Torres-Mazuara, "El ejido posrevolucionario: de forma de tenencia sui generis a forma de tenencia ad hoc", Península VII(2) (2012): 76.

3 Hubert Carton de Grammont, "La presencia norteamericana en el agro sinaloense de la primera mitad del siglo XX", Secuencia Revista de Historia y Ciencias Sociales (7) (1987): 21; María Eugenia Romero-Ibarra, "La reforma agraria de Cárdenas y la industria azucarera de México, I930-I960", Historia Agraria (52) (2010): ir6.

4 Héctor Robles Berlanga y Luciano Concheiro Bórquez, "Vigencia de la reforma agraria en América Latina”, en Agriculturas campesinas en Latinoamérica propuestas y desafíos, ed. Francisco Hidalgo, François Houtart y Pilar Lizárraga, ir6 (Quito: CLACSO, Foro Mundial de Alternativas, Instituto de Altos Estudios Nacionales, La Universidad del Posgrado del Estado, 2014).

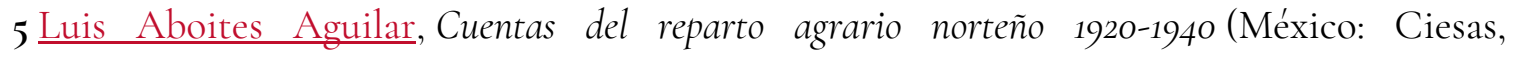
Cuadernos de la Casa Chata, I988), 3 .

6 Ricardo Isaac-Márquez et al., "Programas gubernamentales y respuestas campesinas en el uso del suelo: el caso de la zona oriente de Tabasco". Región y Sociedad XX(43) (2008): 99.

7 Arturo Warman, "Notas para una redefinición de la comunidad agraria", Revista Mexicana de Sociología, año 47(3) (julio-septiembre 1985): 7.

8 Torres-Mazuara, "El ejido", 85.

9 Torres-Mazuara, "El ejido", 82.

Io Gabriela Torres-Mazuara "La flexibilidad y rigidez del ejido como forma de tenencia de la tierra", Relaciones Estudios de Historia y Sociedad (I39) (2014): 257. 
II Teodor Shanin, Naturaleza y lógica de la economía campesina (Barcelona: Anagrama, 1976), 89 .

I2 Luciano Concheiro Bórquez, "Conceptualización del mercado de tierras: una perspectiva campesina", en Mercado de tierras en México, coord. Luciano Concheiro Bórquez, I60-I83 (Roma: FAO, 1995).

I3 Elsa Guzmán Gómez, "Alimentación, soberanía y agricultura campesina”, en Agriculturas campesinas en Latinoamérica propuestas y desafíos, ed. Francisco Hidalgo, François Houtart y Pilar Lizárraga (Quito: CLACSO, Foro Mundial de Alternativas, Instituto de Altos Estudios Nacionales, La Universidad del Posgrado del Estado, 2014), 224.

I4 Concheiro, "Conceptualización", I60-183.

I5 Carpeta básica del ejido Bachoco, enero de 1973.

I6 Carpeta básica del ejido Bachoco, enero de 1973.

I7 Hubert Carton de Grammont, Los empresarios agrícolas y el Estado (México: Instituto de Investigaciones Sociales-Universidad Nacional Autónoma de México, I990), I42-I43.

I8 Carton de Grammont, Los empresarios, I42-I43.

19 Torres-Mazuara, "El ejido", 76.

20 Torres-Mazuara, "La flexibilidad", 277.

2I Acta de la asamblea ejidal de Bachoco del 27 de julio de 1957.

22 Luciano Concheiro Bórquez y Roberto Diego Quintana, "Mercado de tierras en los "tiempos del cólera. Campesinos, tierra y neoliberalismo en México", en Propiedad y organización rural en el México moderno, coord. Julio Moguel, I55 (México: Juan Pablos Editor, 1998).

23 Antonio Escobar Ohmstede, "Cambios en el paisaje hidroagrario. ¿La revolución un detonante?: el caso de San Luis Potosí (r9ro-r940)", Relaciones Estudios de Historia y Sociedad XXXIV(136) (2013): 267.

24 María Luisa Torregrosa, Agua y riego. Desregulación de la agricultura en México (México: Facultad Latinoamericana de Ciencias Sociales, Sede México, 2009), 68.

25 Torregrosa, Agua y riego, 67.

26 Torregrosa, Agua y riego, 60. 
27 Gilberto Giménez y Catherine Héau Lambert, "El desierto como territorio, paisaje y referente de identidad", Culturales III(5) (enero-julio 2007): I2.

28 Francisco Guízar Vázquez, "Estrategias de apropiación territorial y de construcción de hegemonía en un contexto intergrupal: el caso de San Lucas Jalpa, El Mezquital Durango", Relaciones Estudios de Historia y Sociedad XXVI(IоI) (2005): 90.

29 Giménez y Lambert, "El desierto", I2.

30 Mario Sosa Velásquez. "El acaparamiento de tierras y territorios: determinante para la agricultura familiar en América Latina", en Agriculturas campesinas en Latinoamérica propuestas y desafíos, ed. Francisco Hidalgo, François Houtart y Pilar Lizárraga (Quito: CLACSO, Foro Mundial de Alternativas, Instituto de Altos Estudios Nacionales, La Universidad del Posgrado del Estado, 2014), 87 .

3I Carton de Grammont, Los empresarios, I42-I43.

$3^{2}$ Torres-Mazuara, "La flexibilidad", 266.

33 Carlos Rodríguez Wallenius et al., "Escudriñar los enfoques teóricos sobre territorio", en Defensa comunitaria del territorio en la zona central de México. Enfoques teóricos y análisis de experiencias, coord. Carlos Rodríguez, 27-28 (México: Juan Pablos Editor, 20io).

34 Torregrosa, Agua y riego, 9I.

\section{Acta del PROCEDE del ejido Bachoco, Guasa}

\section{Jesús López Estrada}

Egresado del Posgrado en Desarrollo Rural de la Universidad Autónoma Metropolitana Unidad Xochimilco. Profesor investigador de la Universidad Autónoma de Sinaloa. Líneas de investigación: mercado de tierras, tenencia de la tierra, ciudadanía y democracia. Ha publicado capítulos de libro como: "Efectos de la apertura comercial en el campo sinaloense. La disputa por el precio del maíz entre productores y acopiadores en tiempos de sequía". En Crisis alimentaria y sus dilemas tecnológicos y socioambientales. El artículo: "Ciudadanía, democracia y nuevos municipios en Sinaloa”, Revista Ra him hai. Libro: Élites, ciudadanía y nuevos municipios en Sinaloa, coedición UAM-X y UAS. Desde 2018 es miembro del Sistema Nacional de Investigadores. 